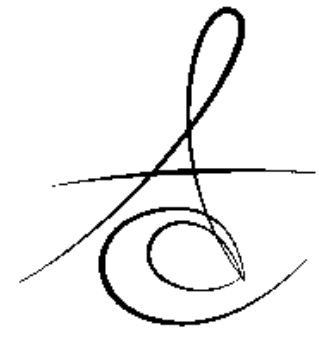

\section{FARKLI İÇERİK VE KALINLIKTAKİ TAM SERAMİK RESTORASYONLARIN TRANSLUSENTLİK DEĞERLERİNİN KARŞILAŞTIRILMASI}

\section{COMPARİSON OF TRANSLUCENCY VALUES OF ALL CERAMİC MATERİALS WİTH DİFFERENT STRUCTURES AND THİCKNESSES}

Yrd. Doç. Dr. Işıl TURP*
Makale Kodu/Article code: 2925

Makale Gönderilme tarihi: 13.07 .2016

Kabul Tarihi; $\quad 27.10 .2016$

\section{öz}

Amaç: Bu çalışmanın amacı farklı kalınlıklarda ve farklı yapıdaki tam seramik materyallerinin translusenstlik değerlerini incelemektir.

Gereç ve Yöntem: Beş farklı seramikten (feldspatik, lösit ile güçlendirilmiş, lityumdisilikat ile güçlendirilmiş, altyapı zirkonya, monolitik zirkonya) ve iki farklı kalınlıkta (0,5-1 mm) örnekler hazırlanmıştır. Her bir grup için örnek sayısı beş olarak saptanmıştır. Örneklerin kontrastlık oranlarını elde etmek için elde etmek için spektrofotometreyle beyaz zemin $\left(L^{*} W\right)$ ve siyah zemin ( $\left.L^{*} b\right)$ üzerinde üçer adet ölçüm gerçekleştirilmiştir. Veriler iki yönlü varyans analizi ile değerlendirilmiştir. Gruplar arası karşılaştırmalar için Tukey's HSD testi kullanılmıştır.

Bulgular: 0,5 mm kalınlıktaki gruplar kendi aralarında karşılaştırıldığında feldspatik ve lösit ile güçlendirilmiş cam seramik dışında bütün gruplar arasında istatistiksel olarak anlamlı farklılıklar görülmüştür. 1 mm kalınlığındaki gruplar kendi aralarında karşılaştırıldığında altyapı zirkonya ve monolitik zirkonya dışında bütün gruplar arasında istatistiksel olarak anlamlı farklılık bulunmuştur.

Sonuç: Kalınlık ve yapısal farklılıklar seramiğin translusensi özelliğini etkilemektedir.

Anahtar Kelimeler: Tam seramik, translusensi, kontrastlık oranı.

\section{ABSTRACT}

Aim: The aim of the study is to evaluate the translucency of all ceramic materials with different thicknesses and structures.

Material and Methods: Specimens with two different thicknesses $(0.5-1 \mathrm{~mm})$ were prepared from five different ceramic materials (feldspathic, leucitereinforced, lithium disilicate reinforced, framework zirconia, monolithic zirconia). Each group contained five specimens. Three measurements were made with spectrophotometry to obtain the contrast ratios of the materials over a white background $\left(\mathrm{L}^{*} \mathrm{~W}\right)$ and a black background $\left(L^{*} b\right)$. The data was analysed by two-way analysis of variance. The groups were compared by Tukey's HSD test.

Results: Groups which have a thickness of $0.5 \mathrm{~mm}$ had statistically significant differences except feldspatic and leucite reinforced ceramic. Groups which have a thickness of $1 \mathrm{~mm}$ had statistically significant differences except framework zirconia and monolithic zirconia.

Conclusion: Thickness and structural differences affects the translucency feature of ceramic.

Keywords: All ceramic, translucency, contrast ratio.

\footnotetext{
* Bezmialem Vakif Universitesi, Dişhekimliği Fakültesi, Protetik Diş Tedavisi AD
} 


\section{GİRİş}

Metal destekli seramik restorasyonlar uzun zamandır kullanılan ve güvenilirliğini kanıtlamış sabit protetik uygulamalardır. Metal alt yapının korozyona maruz kalması, metal alerjisine neden olabilmesi, ve metal altyapının renginin köle bölgesinden yansıyabilmesi bu restorasyonların önemli dezavantajları arasında sayılabilir. ${ }^{1,2}$ Bununla birlikte metal alt yapı ışı̆̆ın yapı içerisinden geçişini önler ve doğal diş görünümünün bütünüyle yansıtılmasını engeller. Günümüzde metal destekli seramik restorasyonlar bu dezavantajları nedeni ile özellikle estetiğin önem kazandığı durumlarda yerini tam seramik restorasyonlara bırakmaktadır. ${ }^{1-3}$

Yapı içerisine giren ışık materyal içerisinde absorbe edilebilir, kırılarak dağılabilir, geri yansıyabilir veya yapı içerisinden geçebilir. ${ }^{4}$ Işığın materyal içesisinde kırılmadan, dağılmadan ve emilmeden geçtiği miktar materyalin translusentliğini vermektedir. Doğal dişte mine ve dentin dokusunun da bir ışık geçirgenliği mevcuttur. ${ }^{4}$ Hazırlanacak olan restorasyonun doğal diş dokusuna yakın translusentliğe sahip olması daha doğal bir görünüm sağlamaktadır. Tam seramik restorasyonlar metal destekli restorasyonlara oranla ışı̆ın geçişine daha fazla izin verirler. Bu sayede dişin doğal görünümüne yakın translusentlik sonuçları elde edilebilmektedir. ${ }^{5}$

Bununla birlikte translusentlik değeri daha doğala yakın seramiklerin kullanımıyla birlikte ışıkla sertleşen adeziv siman sistemlerinin de kullanım imkanı doğmaktadır. Bu şekilde diş ve restorasyon arasında adeziv bağlantı sağlanabilmektedir. Farklı renklerde siman kullanımı ile restorasyon altında doğala yakın renklerde derin yansımalar da elde edilebilmektedir.6, 7

Tam seramik restorasyon tercihinde kulanılacağı bölgenin aldığı çiğneme kuvveti ve gövde uzunluğu dikkate alınmalıdır. ${ }^{8}$ Kullanım alanlarına ve içeriklerine göre piyasada çeşitli tam seramik materyaller bulunmaktadır. Restorasyonun dayanıklıı̆ını arttırmak amacıyla seramik içerisine çeşitli güçlendirici kristal yapılar eklenmektedir. Bu kristal yapılar seramiğin dayanıklılığını artırmakla birlikte restorasyonun translusentliğini etkileyebilir. ${ }^{9-12}$ Optimum estetiğin sağlanması gereken durumlarda bu seramikler içerisinden dişe en yakın traslusentliğe sahip olan seramiği tercih edilmektedir. Fakat yapılacak olan restorasyonla dayanak diş renginin maskelenmesi gereken durumlar da söz konusu olabilmektedir. Bu durumlarda translusentliği daha düşük seramikler tercih edilmelidir. Bu nedenle yapılacak olan restorasyonda hekim tarafından tercih edilecek olan seramiğin translusentliği olguya göre değişmekte ve estetik için önem arz etmektedir.

$\mathrm{Bu}$ çalışmanın amacı tam seramik materyallerinin içeriğinin ve kalınlığının translusentlik üzerine etkisini değerlendirmektir. Çalışmanın sıfır hipotezi; seramik materyalinin içeriğinin veya kalınlığının seramiğin translusentliğini etkilemediğidir.

\section{MATERYAL METOD}

$\mathrm{Bu}$ çalışmada beş farklı seramik incelenmiştir. Her seramik grubu için $0,5 \mathrm{~mm}$ ve $1 \mathrm{~mm}$ kalınlıkta örnekler hazırlanmıştır $(n=5)$. Seramik türleri, içerikleri ve kristal hacim oranları Tablo 1'de görülmektedir.

Tablo 1. Seramik türleri, içerikleri ve kristal hacim oranları

\begin{tabular}{|l|c|c|}
\hline Kullanılan blok & İçerik & $\begin{array}{c}\text { Kristal } \\
\text { hacim } \\
\text { oranı }\end{array}$ \\
\hline $\begin{array}{l}\text { Cerec } \\
\text { blocks(FS) }\end{array}$ & Feldspatik seramik & - \\
\hline $\begin{array}{l}\text { IPS Empress } \\
\text { CAD (LS) }\end{array}$ & Lösit ile güçlendirilmiş seramik & $\% 35-45$ \\
\hline $\begin{array}{l}\text { IPS Emax CAD } \\
\text { (LDS) }\end{array}$ & $\begin{array}{c}\text { Lityum disilikat seramik ile } \\
\text { güçlendirilmiş seramik }\end{array}$ & $\% 70$ \\
\hline $\begin{array}{l}\text { In Coris ZI (ZS) } \\
\text { Yttrium parsiyel stabilize } \\
\text { zirkonyum oksit }\end{array}$ & $\% 99$ \\
\hline $\begin{array}{l}\text { In Coris TZI } \\
\text { (MZS) }\end{array}$ & $\begin{array}{r}\text { Yttrium parsiyel stabilize } \\
\text { zirkonyum oksit }\end{array}$ & $\% 99$ \\
\hline
\end{tabular}

\section{Grup [Feldspatik seramik (FS)]}

Feldspathik seramik örnekler S2-M rengindeki ve orta translusentlikteki CAD-CAM bloğundan (Cerec blocks, Sirona Dental Systems GmbH., Bensheim, Almanya) hazırlandı. Örnekler hassas kesim cihazında (Mecatome T1800, Presi, Grenoble, Fransa) 0,5 ve 1 $\mathrm{mm}$ kalınlığında elmas separeyle (Isomet wafering blades, Buehler, IL) su soğutması altında kesildi. Örnek kalınlıkları dijital kumpas (500-784, Mitutoyo Corp., Kawasaki, Japonya) ile 5 farklı noktadan ölçülerek kontrol edildi. 


\section{Grup [Lösit ile güçlendirilmiş cam seramik (LS)]}

Lösit ile güçlendirilmiş cam seramik örnekler A1 rengindeki ve düşük translusentlikteki CAD-CAM bloktan (IPS Empress CAD, Ivoclar-Vivadent, Schaan, Liechtenstein) hazırlandı. Örnekler FS örneklerin hazırlanmasında kullanılan prosedür kullanılarak hazırlandı.

\section{Grup [Lityum-disilikat ile güçlendirilmiş cam seramik (LDS)]}

Lityum-disilikat ile güçlendirilmiş cam seramik örneklerin hazırlanmasında $\mathrm{A} 1$ rengindeki ve düşük translusentlikteki CAD-CAM blok (IPS E-max CAD, Ivoclar-Vivadent) kullanılarak FS örneklerin hazırlanmasında kullanılan prosedür uygulandı. Bu prosedüre ek olarak örnekler seramiğin final kristalizasyonu için üretici firmanın önerdiği şekilde seramik fırınında (Programat P500/G2, IvoclarVivadent) pişirildi.

\section{Grup [Zirkonya altyapı seramiği (ZS)]}

Örneklerin üretimi için itriyum ile stabilize zirkonya altyapı seramiği blok (inCoris ZI, Sirona Dental Systems $\mathrm{GmbH}$ ) kullanıldı. Üretici talimatları doğrultusunda materyalin büzülme payı göz önüne alınarak örnekler final boyutundan \% 25 daha büyük hazırlandı. Sinterleme işlemi üretici firma talimatları doğrultusunda $15{ }^{\circ} \mathrm{C} / \mathrm{min}$ ısınma hızıyla, $1510{ }^{\circ} \mathrm{C}$ 'de 120 dk süresince gerçekleştirildi. Sinterleme fırınındaki (inFire HTC Speed, Sirona Dental Systems GmbH) sinterizasyon işlemi sırasında örnekler büzülme sonucu istenilen boyuta geldi. Sinterleme işlemi sonrasında örnek kalınlıkları digital kumpas ile beş farklı noktadan ölçüm yapılarak ile kontrol edildi.

\section{(MZS)]}

\section{Grup [Monolitik zirkonya seramik}

Örnekler itriyum ile stabilize monolitik zirkonya seramik bloktan (inCoris TZI, Sirona Dental Systems $\mathrm{GmbH}$ ) hazırlandı. Örnekler ZS grubu örnkeleri gibi final boyutlarından \% 25 daha büyük freze edildi. Sinterleme işlemi üretici firma talimatları doğrultusunda ZS örneklerle aynı şekilde gerçekleştirildi ve örnekler gerçek boyularına ulaştı.

Translusentlik değerleri standart D65 aydınlatma altında beyaz ve siyah zemin üzerinde spektrofotometre (VITA Easyshade Compact, Bad Sackingen, Germany) ile ölçüldü. Herbir örnekten beyaz zemin $\left(L^{*} W\right)$ ve siyah zemin $\left(L^{*} b\right)$ üzerinde 3 'er ölçüm yapıldı. Kontrastlık oranı (contrast ratio [CR]) translusentlik parametresi olarak aşağıdaki formüle göre hesaplandl; ${ }^{13}$

$$
\mathrm{CR}=\mathrm{L}^{*} \mathrm{~b} / \mathrm{L}^{*} \mathrm{~W}
$$

$L^{*} \mathrm{~W}$ :Beyaz zemin üzerindeki yansıma değişimi

$\mathrm{L}^{*} \mathrm{~W}$ : Siyah zemin üzerindeki yansıma değişimi

Formüle göre elde edilen $\mathrm{CR}$ değeri bire yaklaştıkça örneğin beyaz ve siyah zeminler üzerinde elde edilen değerleri arasındaki fark azalmakta ve örnek opağa yaklaşmaktadır. CR değerleri sıfıra yaklaştıkça örneğin beyaz ve siyah zeminler arasındaki değer farkı artmakta ve örnek translusentleşmektedir.

Elde edilen bütün değerlerin istatistiksel analizinde SPSS software version 10.0 (SPSS Inc., Chicago, IL, USA) kullanıldı. Elde edilen veriler çift yönlü ANOVA kullanılarak karşılaştırıldı. Gruplar arası karşılaştırmalar için Tukey's HSD testi kullanıldı.

\section{BULGULAR}

Ortalama translusensi değerleri Tablo 2 ve Şekil 1'de görülmektedir. Çift yönlü Anova ile yapılan istatistiksel değerlendirmede gruplar arasında istatistiksel olarak anlamlı farklılıklar bulunmuştur. Farklı seramiklerin translusentlik değerleri arasında ve aynı seramiğin farklı kalınlıktaki translusentlik değerleri arasında istatistiksel olarak anlamlı farklılıklar görülmüştür.

0,5 mm kalınlığındaki FS ve LS 0,7 CR değeri ile en translusent, $1 \mathrm{~mm}$ kalınlığındaki ZS ve MZS ise 0,83 CR değeri ile en opak gruplar olarak gözlenmiştir. 0,5 mm kalınlığındaki gruplar kendi aralarında karşılaştığında FS ve LS dışında bütün gruplar arasında istatistiksel olarak anlamlı farklılık bulunmuştur. $1 \mathrm{~mm}$ kalınlığındaki gruplar kendi aralarında karşılaştığında ise ZS ve MZS dışında bütün gruplar arasında istatistiksel olarak anlamlı farklılıklar mevcuttur.

Tablo 2. Farklı içerik ve kalınlıktaki seramiklerin ortalama CR değerleri

\begin{tabular}{|l|c|c|}
\hline Kullanılan Blok & \multicolumn{2}{|c|}{$\begin{array}{c}\text { Ortalama CR değerleri ve standart } \\
\text { sapmaları }\end{array}$} \\
\hline & \multicolumn{2}{|c|}{ Kalınlık } \\
\hline & $\mathbf{0 , 5 m m}$ & $\mathbf{1 m m}$ \\
\hline Cerec blocks(FS) & $0.7 \pm 0,0052$ a A & $0.78 \pm 0,0054$ a B \\
\hline $\begin{array}{l}\text { IPS Empress CAD } \\
\text { (LS) }\end{array}$ & $0.7 \pm 0,0048$ a A & $0.79 \pm 0,0051 \quad \mathrm{~b} \mathrm{~B}$ \\
\hline IPS Emax CAD (LDS) & $0.71 \pm 0,006$ b A & $0.80 \pm 0,0055$ c B \\
\hline In Coris ZI (ZS) & $0,72 \pm 0,0055$ c A & $0.83 \pm 0,006 \quad d ~ B$ \\
\hline In Coris TZI (MZS) & $0.74 \pm 0,0062$ d A & $0.83 \pm 0,0042 \quad d ~ B$ \\
\hline
\end{tabular}




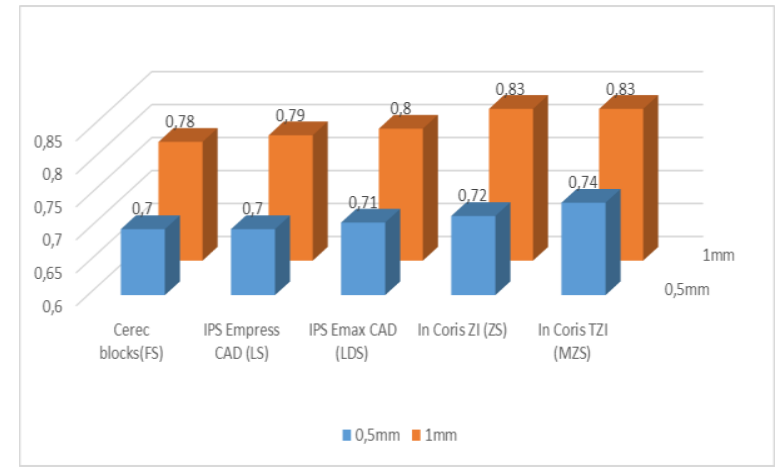

Şekil 1. Farklı içerik ve kalınlıktaki seramiklerin ortalama CR değerleri

\section{TARTIŞMA}

$\mathrm{Bu}$ çalışmada farklı içerik ve kalınlıklardaki seramiklerin translusentlik değerleri karşılaştırılmış ve kalınlık ve seramik içerik farklılıklarının translusentliği etkilemeyeceği yönündeki sıfır hipotezi kabul edilmemiştir. Sonuçlar içerik ve kalınlığın seramik translusentliğini etkilediğini göstermektedir (Tablo 2).

Seramiklerin fırınlanması sırasındaki yapısal değişiklikler, yoğunluk ve porozite miktarı da translusentliği etkileyebilmektedir. ${ }^{14,15}$ Yapı içerisinde meydan gelen porozite hem yapının grenleri arasındaki mesafeyi arttırmakta hem de seramik ile havanın farklı ışık geçirme özellikleri nedeni ile ışığın yapı içerisinde kırılmasına neden olmaktadır. ${ }^{16}$ Çalışmamızda CADCAM bloklardan elde edilmiş materyaller kullanılmıştır. Bu sayede optimum şekilde üretilmiş örnekler kullanılmış ve üretim aşamaları azaltılarak standardizasyonun arttırılması amaçlanmıştır.

Çalışmada translusentlik değerlerinin ölçülmesi için spektofotometre cihazı, materyallerin translusetlik verilerini karşılaştırmak için ise CR (kontrastlık oranı) değeri kullanılmıştır. Literatürde seramiklerin translusentliklerinin değerlendirildiği çalışmalarda genellikle karşılaştırmaların CR değeri veya transparanlık parametresi (TP) kullanılarak yapıldığı görülmektedir. ${ }^{17-20} \mathrm{Bu}$ iki parametrenin karşılaştırıldığı bir çalışmada ise çalışmamızda kullanılan seramik materyalleri için ikisi arasında kuvvetli bir korelasyonun bulunduğu ve ikisinin de kullanılabilir olduğu bildirilmiştir. ${ }^{19}$ Çalışmamızda elde edilen translusentlik verilerini hesaplanma kolaylığı nedeniyle ve diğer çalışmalarla karşılaştırma uygunluğu açısından CR yöntemi tercih edilmiştir.
Çalışmanın bulgularına göre kalınlığın translusentlik üzerinde istatistiksel olarak önemli fark yarattığı bulunmuştur (Tablo 2). Bulgular literatürdeki diğer translusentlik çalışmalarıyla karşılaştırıldığında sonuçların benzer olduğu görülmüştür. ${ }^{21,22,26,31}$ Seramikler materyalin kristal içeriğine bağlı olarak ışığı abzorbe etmekte, yansıtmakta veya ışı̆ın geçişine izin vermektedir. ${ }^{4}$ Seramik kalınlığının artmasıyla ışığın seramik içerisinden geçerken karşılaşacağı seramik partikül sayısının da artacağı bildirilmiştir. Bu durum ışığın yapı içerisinde daha fazla abzorbe edilmesine veya kırılarak dağılmasına neden olmaktadır.

Bununla birlikte çalışmada farklı içerikteki seramiklerin traslusentlikleri arasında da istatistiksel olarak önemli fark elde edilmiştir. Bu farklılığın seramiklerin içerisindeki cam içeriğine, kristal miktarına, bulunan kristallerin büyüklüğüne bağlı olarak değişim gösterebildiği bildirilmiştir. ${ }^{4}$ Firmaların vermiş olduğu kristal içerikleri değerlendirildiğinde kırıma dayanımını artırmak için yapı içerisine eklenen kristal yapı miktarı arttıkça seramiğin ışık geçirgenliğinin düştüğü belirtilmektedir. Tranlusentliğin düşmesinin kristal yapının ışığı abzorbe etmesi ve kırması nedeniyle meydana geldiği düşünülmektedir. ${ }^{4}$

İçeriklerine göre seramikler değerlendirildiğinde cam seramik içeriği yüksek, kristal içeriği düşük seramikler (FS, LS) daha translusent bulunmuştur. Bulgularımız literatürdeki çalışmalarla da paralellik göstermektedir. ${ }^{23,24,26}$ Ayrıca refraktif indeksleri porselen matriksin refraktif indeksine daha yakın olduğu için lösitin ve lityum disilikatın içeriğinde bulunduğu LS ve LDS grupları da zirkonya gruplarına göre (ZS ve MZS) daha translusent saptanmışlardır. ${ }^{23,30}$

Çalışmamızda kristal içeriği en fazla olan zirkonya seramiklerin translusentliği en düşük bulunmuştur. Bu bulgu literatürde zirkonya seramiklerin tranlusentliklerinin oldukça düşük bulunduğu başka çalışmalarla paralellik göstermektedir. Ancak literatürde bu konuda bir fikir birliği bulunmamaktadır. Heffernan ve ark ${ }^{23}$ çalışmalarında In-Ceram Zirconia seramikleri CR değerlerini kontrol grubu olarak belirlenen metal destekli seramik restorasyon altyapısı grubunun değerleri ile benzer bulmuşlardır. Chen ve ark ${ }^{25}$ çalışmalarında Cercon zirkonya altyapı seramiğinin CR değerini 1 bulmuşlar ve opak olarak değerlen- dirmişlerdir. Çalışmamızda ise zirkonya gruplarının CR değerleri kalınlık ve materyale göre değişkenlik göstermekle beraber 0,72-0,83 arasında

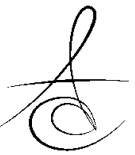


bulunmuştur. Bu değerlerle zirkonya seramik gruplarının çalışma içerisinde diğer gruplara göre daha opak olmalarına rağmen belirli bir translusensi özelliğine sahip oldukları gözlenmiştir.

Çalışmamızda kullanılan zirkonya materyallerinden 0,5 mm kalınlıkta monoklinik zirkonya alt yapı materyali zirkonyadan daha opak bulunmuştur (Tablo 2). Üretici firmanın monoklinik zirkonyayı daha translusent olarak tanıttığı göz önünde bulundurulursa bu oldukça dikkat çekici bir bulgudur. ${ }^{27} 0,5 \mathrm{~mm}$ kalınlığında monolitik zirkonya alt yapı materyali zirkonya ve renklendirilmiş alt yapı materyali zirkonyanın translusentliklerinin ve gren büyüklüklerinin değerlendirildiği bir çalışmada benzer sonuç elde edilmiş ve bu sonuç monolitik zirkonyanın gren büyüklüğünün daha fazla olmasına bağlanmıştır. Yazarlar monolitik zirkonyanın alt yapı materyali zirkonyadan grenlerinin daha büyük olmasının ise materyal içerikleri aynı olduğu için sinterleme ısıları arasındaki farktan kaynaklanabileceğini belirtmişlerdir. ${ }^{28}$ Çalışmamızda da aynı materyaller kullanıldığı için bizim sonuçlarımızın da aynı nedenden kaynaklandığı kanısındayız. Fakat materyal kalınlaştıkça aradaki translusentlik farkı ortadan kaybolmaktadır. $1 \mathrm{~mm}$ kalınlığındaki örneklerde monolitik zirkonya ile alt yapı materyali zirkonya arasında fark bulunmamaktadır.

Alt yapı materyali zirkonya ile insan dentininin translusentlik özelliklerinin karşılaştırıldığı bir çalışmada alt yapı materyali zirkonyanın başarılı bir şekilde dentini taklit edebildiği bildirilmiştir. ${ }^{29}$ Monolitik zirkonyadan üretilmiş bir restorasyonun mine dokusunun da taklit edilebileceği bir vener tabakasının da olmadığı göz önünde bulundurulmalıdır. Monolitik zirkonyanın 0,5 $\mathrm{mm}$ kalınlıkta alt yapı materyali zirkonyaya göre daha opak, $1 \mathrm{~mm}$ kalınlıkta ise aynı translusentlikte olduğu düşünülürse doğal diş dokusun taklit etmekten uzak olduğu sonucuna varılabilir. Estetiğin ön planda olduğu ön bölge restorasyonlarında kullanımında çekimser olunması uygun olacaktır.

Restore edilecek dişin rengi kullanılacak materyalin seçiminde büyük önem kazanmaktadır. Renklenme göstermeyen dayanak dişler alt yapıdan istenmeyen yansımalara neden olmaz; bu nedenle bu tür vakalarda doğal diş translusentliğine yakın seramik materyallerin seçimi daha uygundur. Fakat dayanak olarak kullanılacak dişin devital olması durumunda ya da metal post uygulamalarında alttaki renklenmeyi örtecek şekilde daha opak seramik materyaller tercih edilebilir. Çalışmamız bulgularına göre renklenmiş destek dişlerin maskelenmesi isteniyorsa zirkonya alt yapıların, maskelemeye gerek olmayan destek dişlerin varlığında ise translusentlikleri daha fazla olan feldspatik veya lösit ile güçlendirilmiş seramiklerin kullanımı uygun olacaktır.

\section{SONUC}

1. Seramik kalınlığındaki artış translusentliği azaltmaktadır.

2. Seramik içindeki kristal yoğunluğu arttıkça translusentlik azalmaktadır.

\section{KAYNAKLAR}

1. Joiner A. Tooth colour: a review of the literature. J Dent 2004;32:3-12.

2. Dietschi D. Layering concepts in anterior composite restorations. J Adhes Dent 2001;3:71-80.

3. Ulu $H$, Bayındır $F$. Monolitik zirkonyum restorasyonlar. Atatürk Üniv Diş Hek Fak Derg 2016; Supp 15: 67-72.

4. Clarke FJ. Measurement of color of human teeth. In: McLean JW, editor. Proceedings of the First International Symposium on Ceramics. Chicago: Quintessence; 1983. p. 441-90.

5. Yu B, Ahn JS, Lee YK. Measurement of translucency of tooth enamel and dentin. Acta Odontol Scand 2009;67:57-64.

6. Kramer N, Ebert J, Petschelt A, Frankenberger R. Ceramic inlays bonded with two adhesives after 4 years. Dent Mater. 2006;22:13-21.

7. De Souza G, Braga RR, Cesar PF, Lopes GC. Correlation between clinical performance and degree of conversion of resin cements: a literature review. Appl Oral Sci. 2015 Jul-Aug;23(4):358-68.

8. Raigrodski AJ, Chiche GJ, Potiket N, Hochstedler JL, Mohamed SE, Billiot S, et al. The efficacy of posterior three-unit zirconiumoxide-based ceramic fixed partial dental prostheses: a prospective clinical pilot study. J Prosthet Dent 2006;96:23744.

9. Della Bona A. Bonding to ceramics: scientific evidences for clinical dentistry. Sao Paulo: Artes Medicas; 2009: 252.

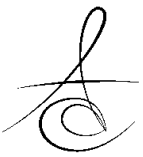


10. Sakaguchi RL, Powers JM. Fundamentals of materials science. In: Sakaguchi RL, Powers JM, editors. Craig's restorative dental materials. 13th ed. Philadelphia: Elsevier Mosby; 2012. p. 33-81

11. Kelly JR, Nishimura I, Campbell SD. Ceramics in dentistry: historical roots and current perspectives. J Prosthet Dent 1996;75:18-32.

12. JA, Miller RB. The effect of core translucency on the aesthetics of all-ceramic restorations. Pract Periodontics Aesthet Dent 1997;9:567-74.

13. Kingery WD, Bowen HK, Uhlmann DR. Introduction to ceramics. 2nd ed. New York; John Wiley and Sons; 1976, p. 646- 89.

14. Berns RS. Principles of color technology. 3rd ed. New York; John Wiley and Sons, Inc; 2000, p. 8-9.

15. Mclean JW. New dental ceramics and esthetics. J Esthet Dent 1995;7:141-9.

16. Zhang HB, Kim BN, Morita K, Yoshida H, Lim JH, Hiraga K. Optimization of high-pressure sintering of transparent zirconia with nano-sized grains. J Alloy Compd 2010;508: 196-9.

17. Li Q, Yu H, Wang YN. Spectrophotometric evaluation of the optical influence of core build-up composites on all-ceramic materials. Dental Materials 2009;25:158-65.

18. Bagis B, Turgut S. Optical properties of current ceramics systems for laminate veneers. Journal of Dentistry 2013;41:24-30.

19. Barizon KTL, Bergeron C, Vargas MA, Qian F, Cobb DS, Gratton DG, et al. Ceramic materials for porcelain veneers. Part I: Correlation between translucency parameters and contrast ratio. J Prosthet Dent 2013;110:397-401.

20. Heffernan MJ, Aquilino SA, Diaz-Arnold AM, Haselton DR, Stanford CM, Vargas MA. Relative translucency of six all-ceramic systems. Part I: core materials. J Prosthet Dent 2002;88:4-9.

21. Holloway JA, Miller RB. The effect of core translucency on the aesthetics of all-ceramic restorations. Pract Periodontics Aesthet Dent 1997;9:567-74.

22. Antonson SA, Anusavice $\mathrm{KJ}$. Contrast ratio of veneering and core ceramics as a function of thickness. Int J Prosthodont 2001;14:316-20.

23. Heffernan MJ, Aquilino SA, Diaz-Arnold AM, Haselton DR, Stanford CM, Vargas MA. Relative translucency of six all-ceramic systems. Part I: core materials. J Prosthet Dent 2002;88:4-9.
24. Heffernan MJ, Aquilino SA, Diaz-Arnold AM, Haselton DR, Stanford CM, Vargas MA. Relative translucency of six all-ceramic systems. Part II: core and veneer materials. J Prosthet Dent 2002;88:10-5.

25. Chen YM, Smales RJ, Yip KH, Sung WJ. Translucency and biaxial flexural strength of four ceramic core materials. Dent Mater 2008,24:150611.

26. Wang F, Takahashi H, Iwasaki N. Translucency of dental ceramics with different thicknesses. J Prosthet Dent 2013;110:14-20.

27. Zirkonzahn web sitesi. http://www.zirkonzahn. com/en/prettau-zirconia/prettau-zirconia. Erişim: 24-09-2016.

28. Tuncel İ, Turp I, Üşümez A. Evaluation of translucency of monolithic zirconia and framework zirconia materials. J Adv Prosthodont 2016;8:1816.

29. Pecho OE, Ghinea R, Ionescu AM, Cardona Jde L, Paravina RD, Pérez Mdel M. Color and translucency of zirconia ceramics, human dentine and bovine dentine. J Dent 2012;40:e34-40.

30. Ding $Y$, Jiang S, Luo T, Miura $Y$, Peyghambarian N. Lithium disilicate crystalline slab waveguides from surface crystallised glass. Electronics Letters 1999;35:504-5.

31. Kursoglu P, Karagoz Motro PF, Kazazoglu E. Translucency of ceramic material in different coreveneer combinations. J Prosthet Dent 2015;113:48-53.

\footnotetext{
Yazışma Adresi

Yrd. Doç. Dr. İlkin Tuncel

Bezmialem Vakif Universitesi,

Dişhekimliği Fakültesi,

Protetik Diş Tedavisi AD., 34093, Fatih / İstanbul, Turkiye

Tel: +902124531700

Fax: +902125230876

E-mail: ilkint@hotmail.com
} 